\title{
Burden and Trend of Measles in Nigeria: Five-year Review Case-base Surveillance Data
}

\author{
Baffa S. Ibrahim ${ }^{\star 1,2}$, Yahaya Mohammed ${ }^{2}$, Rabi Usman², Aisha Abubakar ${ }^{3}$ and \\ Patrick Nguku²
}

${ }^{1}$ Center for International Health, Education and Biosecurity, University of Maryland Global Initiative, Abuja, Nigeria; ${ }^{2}$ Nigeria Field Epidemiology and Laboratory Training Program, Abuja, Nigeria; ${ }^{3}$ Ahmadu Bello University, Zaria, Nigeria

\section{Objective}

We reviewed measles specific Integretaged Disease Surveillance and Response (IDSR) data from Nigeria over a five-year period to highlights its burden and trends, and make recommendations for improvements.

\section{Introduction}

Measles is a vaccine preventable, highly transmissible viral infection that affects mostly under-five year children. The disease is caused by a Morbillivirus; member of the Paramyxovirus family.

\section{Methods}

We conducted a secondary data analysis of measles specific IDSR records of all States in Nigeria from January 2012 to September 2016. The record had reported measles cases with laboratory outcomes from all the States. IDSR weekly epidemiological data were obtained from Surveillance Unit, Nigerian Centre for Disease Control (NCDC).

\section{Results}

A total of 131,732 cases were recorded within the period. Highest number of cases 57,892(43.95\%) were recorded in 2013 while the least number of cases $11,061(8.4 \%)$ were recorded in 2012. A total of 817 deaths were recorded, giving a case fatality rate (CFR) of $0.62 \%$. The CFR showed a decreasing trend over the years with the highest CFR (1.43\%) recorded in 2012 and the least CFR (0.44\%) recorded in 2016. Only $8,916(6.7 \%)$ cases were confirmed by laboratory investigation. The Northwest region recorded the highest attack rate (AR) of 149.7 cases per 100,000 population, followed by the Northeast region with 140.2 cases per 100,000 population, while the South-south region recorded the least AR of 15.8 cases per 100,000 population. CFR per region followed similar pattern, with the Northcentral region having the highest CFR of $4.38 \%$. The trend of measles cases followed the same pattern. Cases peaked at March, then gradually reduced to lowest level in June.

\section{Conclusions}

Measles infection remains a burden especially in the northern region of Nigeria. Though measles fatalities were on decline over the years, laboratory diagnosis of cases has been suboptimal. We recommended improvement on routine immunization and measles case management, and strengthening of regional laboratories capacity for measles diagnosis.

Regional and yearly distribution of number of cases, number of deaths, attack rates and case fatality rates for measles cases in Nigeria from January 2012 to September 2016

\begin{tabular}{|c|c|c|c|c|c|}
\hline Regions & Projected Pop & Cases & Deaths & $\begin{array}{c}\text { Attack Rate } \\
\text { per 100,000 }\end{array}$ & CFR \% \\
\hline North-west & $45,667,564$ & 68,380 & 429 & 149.73 & 0.63 \\
\hline North-east & $24,469,020$ & 34,310 & 816 & 140.22 & 2.38 \\
\hline North-central & $26,819,540$ & 10,051 & 440 & 37.48 & 4.38 \\
\hline South-west & $35,544,233$ & 9,544 & 16 & 26.85 & 0.17 \\
\hline South-east & $20,622,822$ & 5,498 & 202 & 26.66 & 3.67 \\
\hline South-south & $26,926,140$ & 4,257 & 31 & 15.81 & 0.73 \\
\hline
\end{tabular}

Distribution of number of cases, deaths, and case fatality rates for measles cases in Nigeria from January 2012 to September 2016.

\begin{tabular}{|c|c|c|c|c|}
\hline Year & Cases & Percent & Deaths & CFR \% \\
\hline 2012 & 11,061 & 8.40 & 158 & 1.43 \\
\hline 2013 & 57,892 & 43.95 & 348 & 0.60 \\
\hline 2014 & 15,989 & 12.14 & 85 & 0.53 \\
\hline 2015 & 24,421 & 18.54 & 127 & 0.52 \\
\hline 2016 & 22,369 & 16.98 & 99 & 0.44 \\
\hline Total & 131,732 & 100 & 817 & 0.62 \\
\hline
\end{tabular}

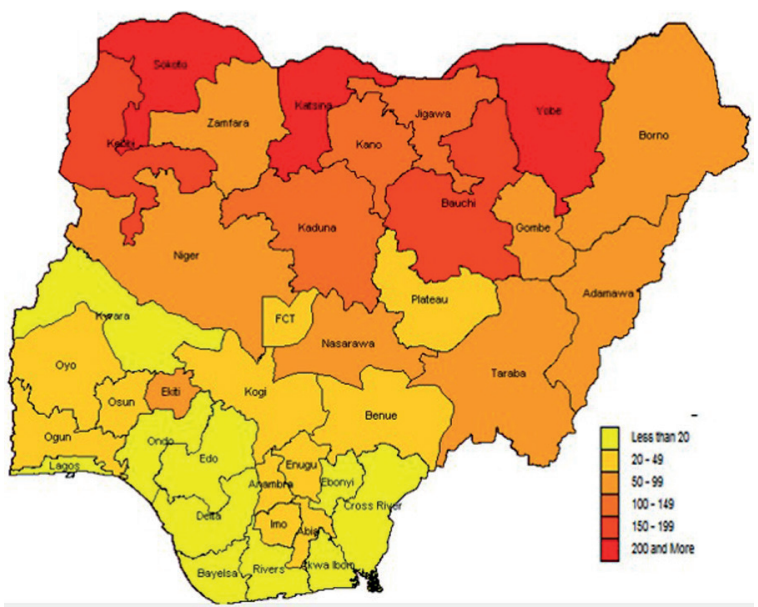

Map of Nigeria showing measles attack rate per 100,000 population across the States, 2012 - 2016

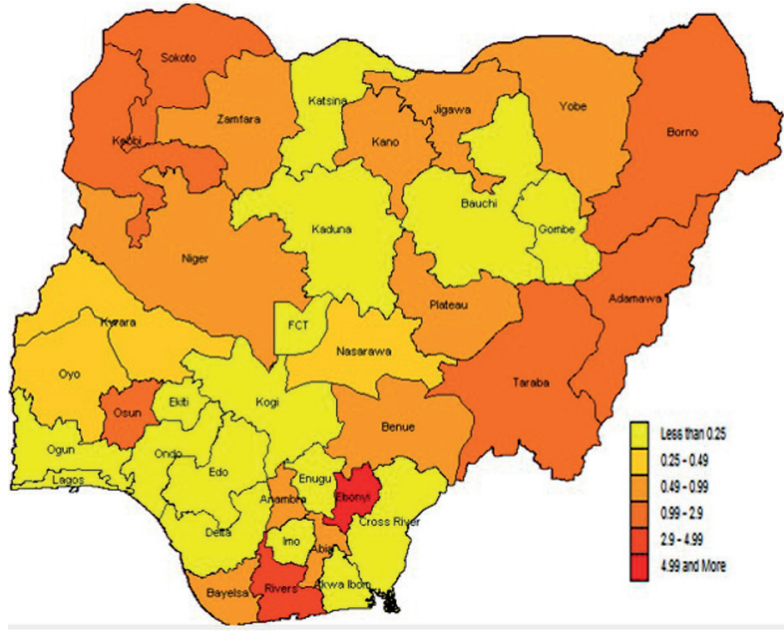

Map of Nigeria showing measles case fatality rates (CFR) across the States, $2012-2016$ 


\section{ISDS 2018 Conference Abstracts}

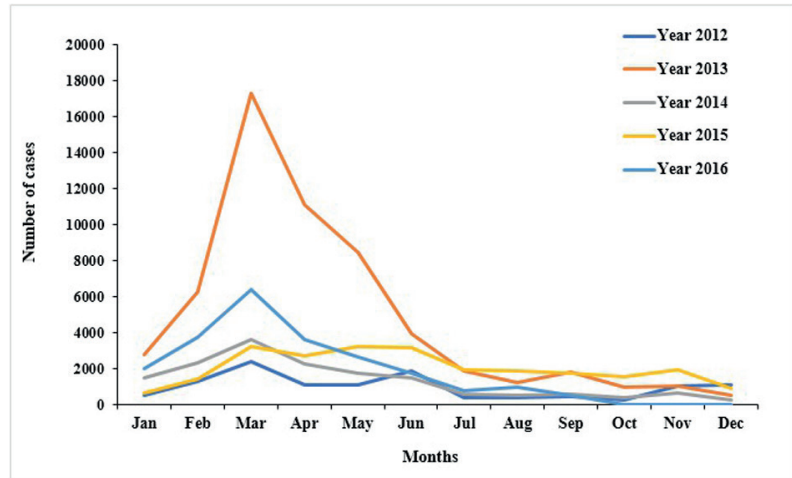

Comparative yearly trend of measles cases in Nigeria from 2012 to 2016 .

\section{Keywords}

Disease Outbreak; Measles; Nigeria; Vaccination

\section{Acknowledgments}

Authors gratefully acknowledge Nigeria Field Epidemiology and Laboratory Training Program and all staff of the Nigeria Center for Disease Control (NCDC) for their support.

\section{References}

1. WHO | Measles. WHO [Internet]. World Health Organization; 2017 [cited 2017 Apr 10]; Available from: http://www.who.int/mediacentre/ factsheets/fs286/en/

2. Akande TM. A review of measles vaccine failure in developing countries. Niger. Med. Pract. SAME Ventures; 2007;52:112-6.

3. Ibrahim BS, Gana GJ, Mohammed Y, Bajoga UA, Olufemi AA, Umar AS, et al. Outbreak of measles in Sokoto State North-Western Nigeria, three months after a supplementary immunization campaign: An investigation report 2016. Australas. Med. J. 2016;9:324-35.

\section{*Baffa S. Ibrahim}

E-mail: baffasule@gmail.com 